\title{
The study on minimum uncut chip thickness and cutting forces during laser-assisted turning of $\mathrm{WC} / \mathrm{NiCr}$ clad layers
}

\author{
${\text { D. } \text { Przestacki }^{1} \text { - T. Chwalczuk }}^{1} \cdot$ S. Wojciechowski ${ }^{1}$
}

Received: 28 October 2016 / Accepted: 9 January 2017 /Published online: 1 February 2017

(C) The Author(s) 2017. This article is published with open access at Springerlink.com

\begin{abstract}
Laser cladding technology enables the regeneration or manufacturing of machine parts with the improved surface layer properties. The materials applied during the laser cladding processes very often contain hard and wear-resistant tungsten carbide (WC) particles. However, the parts obtained after the laser cladding have usually unsatisfactory surface quality and thus require post-process finishing. In addition, the content of WC particles causes that clad layers are difficult to cut. Therefore, in order to improve their machinability, the laser-assisted machining (LAM) technology can be applied. Nevertheless, the material removal mechanisms during LAM of WC/NiCr clad layers are not recognized. Thus, this study is focused on the estimation of minimum uncut chip thickness and analysis of cutting forces which are important factors describing the chip decohesion process. The proposed method is based on the novel approach dedicated directly to the oblique cutting, considering the zeroth tangential force increment located onto rounded cutting edge. The experimental procedure involves cutting force component $\left(F_{c}, F_{f}, F_{p}\right)$ measurements in the range of variable cutting conditions, as well as the cutting tool's micro-geometry inspection. On the basis of the measurements carried out, the force regression equations are formulated and subsequently applied to the determination of tangential force expression. Subsequently, the minimum uncut chip thickness is calculated on the basis of the equation derived from the zero tangential force increment condition and presented in function of cutting speed. The obtained
\end{abstract}

S. Wojciechowski sjwojciechowski@o2.pl

1 Poznan University of Technology, Piotrowo 3, 60-965 Poznan, Poland results enable the effective selection of the cutting parameters during $\mathrm{LAM}$ of $\mathrm{WC} / \mathrm{NiCr}$ clad layers.

Keywords Laser-assisted machining (LAM) · Minimum uncut chip thickness $\cdot$ Laser clad WC/NiCr layers $\cdot$ Cutting forces

\section{Introduction}

Laser cladding is one of the layer manufacturing (LM) processes, applied for production of complex parts by consolidating successive layers of powder material on top of each other [1]. This technology, which is commercially known as LENS (laser-engineered net shaping), involves the application of high power lasers (500 W-4 kW) [2]. The primary objective of cladding is the regeneration or manufacturing of machine parts with the improved surface layer properties, e.g. the increased corrosion resistance, wear resistance and heat resistance [3]. Nevertheless, the parts produced by cladding technology have an unsatisfactory geometric accuracy and high surface roughness [4]. Thus, in order to produce the finished parts with high surface quality and high productivity, the processes which perform both cladding and machining can be applied. In example, Hur et al. [5] developed the hybrid manufacturing system consisting of deposition station and $\mathrm{CNC}$ machining centre. Jeng and Lin [6] designed the hybrid processes of selective laser cladding and milling. Cus et al. [2] carried out the milling process of the laser cladded material in order to improve the machined surface quality.

The frequently applied highly resistant materials used for cladding processes consist of $\mathrm{WC} / \mathrm{Co}, \mathrm{WC} / \mathrm{Ni}, \mathrm{WC} /$ Stellite, $\mathrm{WC} / \mathrm{W}_{2} \mathrm{C}$ and $\mathrm{WC} / \mathrm{NiCr}$ powder mixtures [7-10]. The participation of tungsten carbide (WC) particles in the manufactured clads causes mainly the improvement of its hardness, wear 
resistance and toughness. Unfortunately, the materials based on hard and brittle tungsten carbide particles are extremely difficult to cut. Therefore, the development of the productive and economic cutting technology of these materials is of high importance.

One of the technologies, which can be applied for the finishing of hard and brittle materials, is ultraprecision cutting. This method is based on brittle-ductile transition of work material during the chip formation. According to Bifano et al. [11], the decohesion of the material in the ductile regime occurs when the selected maximum uncut chip thickness is less than the critical depth of cut that involves cracking. The research carried out by Stephenson et al. [12] proved that the application of ultraprecision grinding of hardened steel in the ductile mode reduces the amount of cracks and damages on the machined surface, as well as improves its geometrical accuracy. In addition, the ductile cutting of brittle materials has been also conducted for the tools with defined geometry. However, this process is feasible when the quotient of cutting edge radius to uncut chip thickness is greater than unity [13]. As an example, Liu et al. [14] carried out the grooving tests of $\mathrm{WC} / \mathrm{Co}$ samples, with the use of cubic boron nitride inserts. The results have shown that the transition from the brittle to ductile regime cutting occurs when the uncut chip thickness was lower than $2.5 \mu \mathrm{m}$. The next research carried out by Liu et al. [15] included milling tests of tungsten carbide P30 with the application of ultraprecision machine tool and cubic boron nitride end mill. It was observed that during ductile mode milling, the average surface roughness values were below $0.2 \mu \mathrm{m}$ and were independent of cutting speed. The ultraprecision diamond turning of brittle reaction-bonded silicon carbide (RB-SiC) was carried out by Yan et al. [16]. It was stated that mechanism for material removal induced ductile cutting, cleavage cracking and grain dislodgement. The research carried out by Twardowski [17] was focused on the analysis of surface roughness and tool wear during end milling of tungsten carbide layers manufactured by the direct laser deposition (DLD) technology. It was shown that surface roughness after precision milling is comparable with that obtained after grinding. Nevertheless, the abrasion of hard WC particles onto the tool flank face causes rapid tool wear.

The above deliberations reveal that ultraprecision cutting can be applied for the finishing of hard and brittle materials. However, the effective application of this technique requires the use of specialist machine tools characterized by the high rigidity, damping and precision of control. Furthermore, the excessive tool wear occurring during the ultraprecision cutting can significantly reduce its profitability.

Therefore, another technology which can be successfully applied to precision cutting of hard and brittle materials is laser-assisted machining (LAM). The LAM is promising and developing technology which uses a high power laser in order to heat the work material before the chip formation induced by the single point cutting tool [18]. According to authors of [19-21], the application of laser-assisted machining leads to the improvement in machined surface quality, growth of material removal rate, significant reduction in the tool wear and growth of process dynamic stability, as well as the possibility to cut hard and brittle materials in the ductile mode. The LAM process has been successfully applied to improve the machinability of variety of hard-to-cut materials such as metals [22, 23], ceramics [24, 25] and metal matrix composites [26-29]. Nevertheless, the use of this technique towards the materials consisting tungsten carbide particles was not reported in the literature. Therefore, the material removal mechanisms during LAM of this group of materials are not recognized.

One of the fundamental factors describing the chip decohesion process is minimum uncut chip thickness. This quantity characterizes the value of critical chip thickness, which initiates the material shearing and transition into the chip. During the precision cutting of hard-to-cut materials, the selected uncut chip thickness values are in range of minimum uncut chip thickness, which can consequently lead to the growth of ploughing forces and thus to the accelerated tool wear, rough surface finish and elastic recovery of the work piece [30]. Generally, the minimum uncut chip thickness is depended on the cutting edge radius and properties of the work material. Nevertheless, this quantity is very difficult to directly measure during the machining process. Thus, many authors have estimated minimum uncut chip thickness on the basis of the analytical, numerical and experimental predictions. For example, Camara et al. [31] estimated minimum uncut chip thickness during micro-milling of AA 6262-T6 alloy, on the basis of the measured acoustic emission signals. F.B. de Oliveira et al. [32] empirically determined the minimum uncut chip thickness by combining the chip formation, work piece roughness and specific cutting force during micromilling of AISI 1045 steel. Kragelsky et al. [33] experimentally stated that minimum uncut chip thickness depended on cutting edge radius, the flow stress of strain-hardened bulk material and the shear strength of the adhesive joint at the tool-chip interface. Their approach has been extended and further applied by Liu et al. [34] to the prediction of minimum uncut chip thickness during micro end milling of 1040 steel and A16082-T6 alloy. The minimum uncut chip thickness has been also estimated on the basis of the finite elements (FE) models. This kind of approach has been adopted by Lai et al. [35] and Moriwaki et al. [36] during orthogonal micro-cutting of copper. The alternative analytical methods are based on the identification of the stagnation point on the cutting edge radius with the consideration of minimum cutting energy or minimum tangential force. Malekian et al. [37] predicted the minimum uncut chip thickness during the micro-milling of the Al6061 alloy with the use of minimum cutting energy approach. The necessary model parameters were experimentally obtained from the orthogonal cutting tests. The similar method 
has been applied by Storch and Zawada-Tomkiewicz [38]. The proposed model was formulated for the orthogonal turning and based on the determination of critical angle in the cutting edge's cross-section, corresponding to zeroth tangential force.

The state of the art presented above reveals that there is a lack of research dedicated precisely to the chip formation mechanisms and investigation of minimum uncut chip thickness during machining of hard clad layers, consisting tungsten carbide. In addition, the problem of minimum uncut chip thickness identification during LAM processes was also not reported in the literature. Therefore, in this paper, the minimum uncut chip thickness during laser-assisted machining of $\mathrm{WC} / \mathrm{NiCr}$ clad layers is estimated. The proposed approach is based on the novel method dedicated precisely to the oblique cutting processes; however, the majority of models presented in the literature are devoted to the orthogonal cutting. The proposed method considers the identification of the minimal tangential force acting on the rounded cutting edge. Thus, the investigations presented in the paper are also focused on the relations between the cutting parameters and generated cutting forces. The experimental procedure involves cutting force component $\left(F_{c}, F_{f}, F_{p}\right)$ measurements in the range of variable cutting conditions and cutting tool's micro-geometry inspection. On the basis of the measurements carried out, the force regression equations are formulated and subsequently applied to the determination of tangential force expression. In the next step, the minimum uncut chip thickness is calculated on the basis of the equation derived from the zero tangential force increment condition. The obtained results are presented in function of cutting speed.

\section{Minimum uncut chip thickness model}

In conventional (macro) machining operations, it is usually assumed that the tool has an ideally sharp edge (the cutting edge radius $r_{n}=0$ ) and thus the material removal mechanism is independent on elastic-plastic deformations occurring in the work material-tool's flank interface. However, this assumption is not acceptable during the precision cutting of hard-tocut materials, in which the selected uncut chip thickness value $h$ is usually in order of the curved cutting edge radius $\left(r_{n}>0\right)$ and thus similar to minimum uncut chip thickness (Fig. 1a). Consequently, the work material which has the thickness lower than minimum uncut chip thickness $\left(h<h_{\min }\right)$ is not being cut but is ploughed and pressed under the tool's flank face (see-Fig. 1b). This phenomenon is induced mainly by the elastic-plastic characteristic of the work material, as well as the appearance of curved cutting edge radius $r_{n}>0$. This deformed material generates ploughing force acting on the tool's flank face $A_{\alpha}$, which can consequently lead to the excessive tool wear, deterioration of surface roughness and elastic recovery of the work piece.

It should be noted that work material's flow direction towards the cutting edge during machining affects the direction of the tangential force increment $\Delta F_{t n}$ (see-Fig. 1), located along the curved edge radius. In addition, the stagnant point A, located onto the curved edge radius, defines the area of work material's separation and thus corresponds to the minimum uncut chip thickness. Therefore, the problem of minimum uncut chip thickness estimation can be limited to the finding of the stagnant point A.

According to the authors of [37, 38], the location of stagnant point $\mathrm{A}$ is described by the occurrence of the minimum cutting energy or the tangential force increment equaled to zero. In this study, the zeroth tangential force method, proposed by Storch and Zawada-Tomkiewicz [38], is applied and extended to the oblique cutting of $\mathrm{WC} / \mathrm{NiCr}$ clad layers. During the oblique cutting with the rounded corner of insert $\left(r_{\varepsilon}>0\right)$, the instantaneous uncut chip thickness values are variable in function of width of cut, which affects the distribution of cutting force components and thus hinders the estimation of minimum uncut chip thickness. Therefore, in order to simplify the deliberations, it was assumed that cutting force components and their increments $\left(\Delta F_{c i}, \Delta F_{f i}, \Delta F_{p i}\right)$ are located in the centre of gravity of the chip cross-section (seeFig. 2).

The first stage of minimum uncut chip thickness calculation involves the formulation of cutting force components' equations. The literature shows that cutting forces can be estimated on the basis of the analytical and experimental approaches. The first group of models consider the thermomechanical and tribologic phenomena occurring during the chip removal process. Nevertheless, the significant constraint of these approaches is the necessity of the accurate determination of factors characterizing material decohesion process, as shear stress, shear angle and tool-chip interface friction coefficient, as well as chip flow angle [39]. Unfortunately, these quantities are still unidentified for the $\mathrm{WC} / \mathrm{NiCr}$ materials. Thus, the cutting forces during machining of this group of materials can be estimated on the basis of the simpler experimental-statistical methods. The application of these models requires only the measurements of cutting forces for the various input parameters. Subsequently, the force regression equations can be formulated on the basis of the least squares method.

In this study, the experimental linear force model in function of uncut chip thickness has been adapted, which is described by the following equations:

$$
\begin{aligned}
& F_{c}=C_{c} \cdot h_{c}+F_{c e}[\mathrm{~N}] \\
& F_{f}=C_{f} \cdot h_{c}+F_{f e}[\mathrm{~N}] \\
& F_{p}=C_{p} \cdot h_{c}+F_{p e}[\mathrm{~N}]
\end{aligned}
$$


(a)

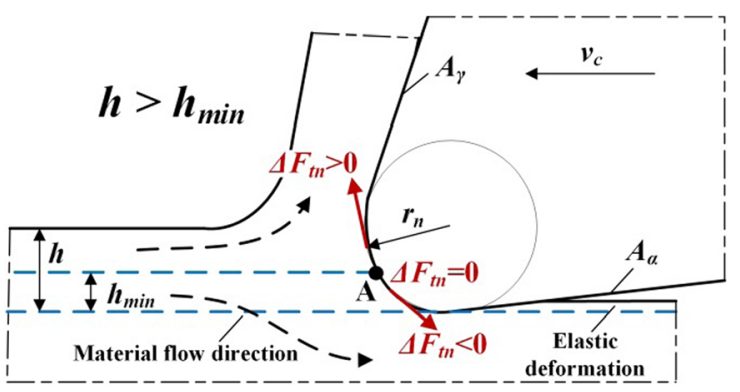

(b)

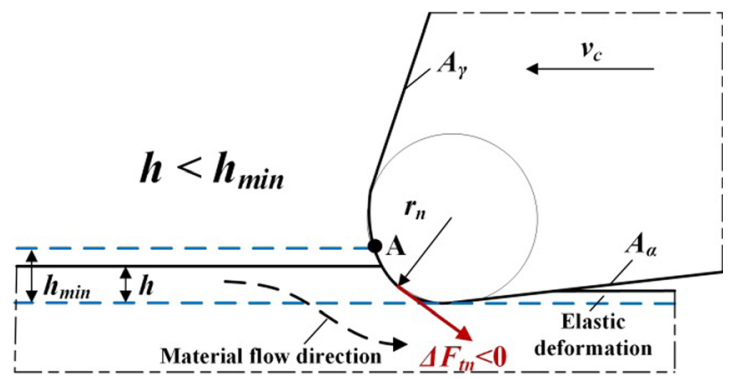

Fig. 1 Orthogonal cutting with rounded cutting edge, when $\mathbf{a} h>h_{\min }$ and $\mathbf{b} h<h_{\min }$

where $C_{c}, \mathrm{C}_{f}$ and $C_{p}$ are the empirical slope coefficients of the $F_{c}, F_{f}$ and $F_{p}$ forces, $h_{c}$ is the uncut chip thickness defined in the plane tangent to chip cross-section's centre of gravity (see-Fig. 2a) and $F_{c e}, F_{f e}$ and $F_{p e}$ are the intercepts of regression equations, corresponding to the edge forces.

The uncut chip thickness $h_{c}$ contained in Eqs. (1a)-(1c) can be calculated from the following equation:

$h_{c}=r_{\varepsilon}+f \cdot \sin \varphi_{c}-\sqrt{r_{\varepsilon}^{2}-f^{2} \cdot \cos \varphi_{c}}[\mathrm{~mm}]$

where $r_{\varepsilon}$ is the corner radius of insert [mm], $f$ is the feed per revolution $[\mathrm{mm} / \mathrm{rev}]$ and $\varphi_{c}$ is the position angle of uncut chip thickness $h_{c}$ [rad].

In order to solve Eq. (2), one should determine the position angle of uncut chip thickness $\varphi_{c}$. This factor can be obtained from the following expression:

$\varphi_{c}=\frac{2 \cdot l_{c}}{3 \cdot r_{\varepsilon}}-\arccos \left(1-\frac{f^{2}}{8 r_{\varepsilon}^{2}}\right)[\mathrm{rad}]$

The $l_{c}$ factor contained in Eq. (3) can be determined on the basis of the following equation:

$l_{c}=\sqrt{r_{\varepsilon}^{2}\left[\arccos \left(1-\frac{a_{p}}{r_{\varepsilon}}\right)+\arccos \left(1-\frac{f^{2}}{8 r_{\varepsilon}^{2}}\right)\right]^{2}-\frac{f^{2}}{4}}[\mathrm{~mm}]$

(a)

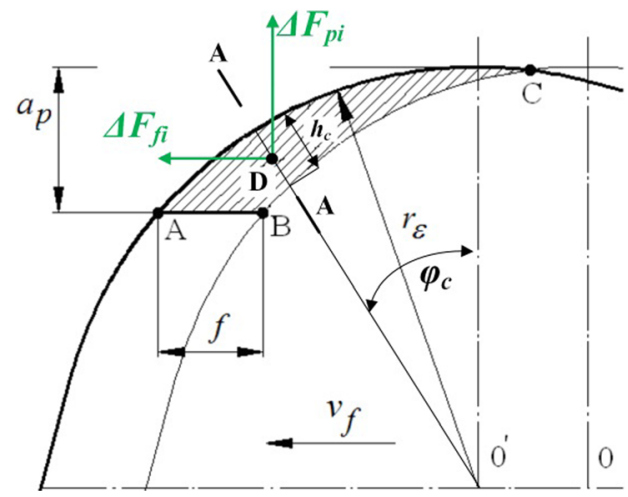

The obtained force regression equations (1a-1c) allow the calculation of the cutting force components' increments $\Delta F_{c i}$, $\Delta F_{f i}, \Delta F_{p i}$ for the $i$-th uncut chip thickness, on the basis of:

$\Delta F_{c i}=C_{c} \cdot \Delta h[\mathrm{~N}]$
$\Delta F_{f i}=C_{f} \cdot \Delta h[\mathrm{~N}]$
$\Delta F_{p i}=C_{p} \cdot \Delta h[\mathrm{~N}]$

where $\Delta h=h_{l}-h_{i-1}$ is the increment of uncut chip thickness [mm].

The cutting force component increments' $\Delta F_{c i}, \Delta F_{f i}, \Delta F_{p i}$ equations are further applied to the determination of tangential force increment expression, based on the geometric dependencies depicted in Fig. 2b:

$\Delta F_{t n i}=\left(\Delta F_{f i} \cdot \sin \varphi_{c}+\Delta F_{p i} \cdot \cos \varphi_{c}\right) \cdot \cos \left|\gamma_{n i}\right|-\Delta F_{c i} \cdot \sin \left|\gamma_{n i}\right|[\mathrm{N}]$

where $\gamma_{n i}$ is the normal rake angle obtained for the $i$-th uncut chip thickness [rad].

In order to calculate the minimum uncut chip thickness $h_{\min }$, one should assume that

$$
\begin{aligned}
& \Delta F_{t n}\left(h_{\min }\right) \\
& \quad=\left(\Delta F_{f i} \cdot \sin \varphi_{c}+\Delta F_{p i} \cdot \cos \varphi_{c}\right) \cdot \cos \left|\gamma_{n}\left(h_{\min }\right)\right|-\Delta F_{c i} \cdot \sin \left|\gamma_{n}\left(h_{\min }\right)\right|=0
\end{aligned}
$$

(b)

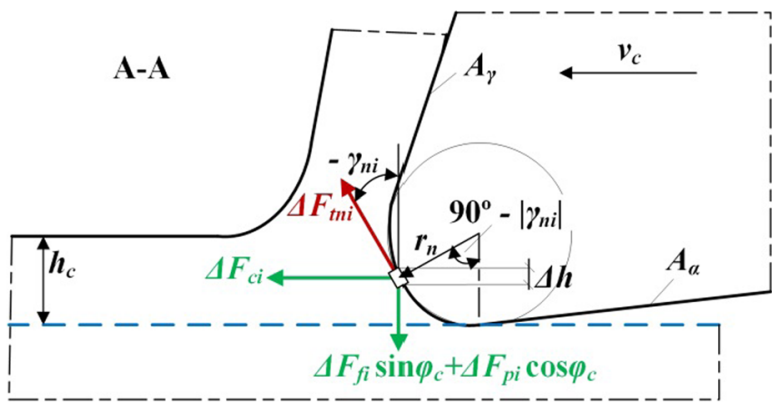

Fig. 2 The distribution of the force increments during oblique turning. a The designation of the $\Delta F_{f i}, \Delta F_{p i}$. b The designation of the $\Delta F_{c i}, \Delta F_{t n i}$ 
The determination of the $h_{\min }$ from Eq. (7) can be made, assuming that:

$\left|\gamma_{n}\left(h_{\mathrm{min}}\right)\right|=\arcsin \left(1-\frac{h_{\mathrm{min}}}{r_{n}}\right)[\mathrm{rad}]$

Ultimately, after the transformations, the minimum uncut chip thickness can be calculated from the following equation:

$h_{\min }=r_{n}\left[1-\sin \left(\arctan \left(\frac{C_{f} \cdot \sin \varphi_{c}+C_{p} \cdot \cos \varphi_{c}}{C_{c}}\right)\right)\right][\mu \mathrm{m}]$

Equation (9) reveals that the estimation of minimum uncut chip thickness requires the determination of cutting force regression equations and the measurement of cutting edge radius' value $r_{n}$, as well as the knowledge of tool's corner radius $r_{\varepsilon}$. The general scheme of the proposed minimum uncut chip thickness model is given in Fig. 3.

\section{Experimental details}

\subsection{Work and tool materials}

The investigations were carried out on low carbon steel samples with $\mathrm{WC} / \mathrm{NiCr}$ coatings produced by the laser cladding process. These samples were manufactured by the Plasma SYSTEM company. The investigated material contains the $88 \%$ of WC reinforcing phase and $12 \%$ of the NiCr matrix. The nominal carbide size was equaled to 40-160 $\mu \mathrm{m}$ [40]. The thickness of the $\mathrm{WC} / \mathrm{NiCr}$ clad layer was of $2.1 \mathrm{~mm}$. The samples had cylindrical shape and $d \approx 52 \mathrm{~mm}$. The chemical composition of the NiCr matrix is depicted in Table 1. The microstructure of the sample is shown in Fig. 4. The mean nano-hardness values of the reinforcing $\mathrm{WC}$ phase and $\mathrm{NiCr}$ matrix were equaled to, namely, 1316 and $859 \mathrm{nHV}$.

In order to increase laser beam absorption during the LAM process, the samples were painted twice with an absorptive coating (gouache).
Table 1 The chemical composition of the NiCr matrix

\begin{tabular}{lllllllll}
\hline Element & $\mathrm{C}$ & $\mathrm{Fe}$ & $\mathrm{Si}$ & $\mathrm{B}$ & $\mathrm{Cr}$ & $\mathrm{Co}$ & $\mathrm{Ni}$ \\
\hline Content in weight [\%] & $<0.6$ & $2.6-3.4$ & $3.4-3.9$ & $1-1.3$ & $6-8$ & $<0.1$ & $\mathrm{Bal}$. \\
\hline
\end{tabular}

The laser-assisted turning tests (LAM) were carried out with the application of the polycrystalline diamond KD100 inserts with the TPGN110304F symbol and the following geometry: orthogonal flank angle $\alpha_{o}=11^{\circ}$, orthogonal rake angle $\gamma_{o}=0^{\circ}$ and corner radius $r_{\varepsilon}=0.4 \mathrm{~mm}$.

In order to determine the cutting edge radius $r_{n}$ of the cutting insert, the inspection of tool's micro-geometry with the application of the Alicona IF-Edgemaster optical device was carried out. The measurements were conducted for the eight different sections of the cutting edge, located in the tool's corner. The mean arithmetic value of cutting edge radius was obtained as $r_{n}=7.1 \mu \mathrm{m}$.

\subsection{Research range and method}

The experiments carried out involved the longitudinal turning tests of the $\mathrm{WC} / \mathrm{NiCr}$ samples in the laser-assisted machining (LAM) conditions. The LAM stand was equipped with Trumpf TruDiode 3006 laser (with maximum power $P=3000 \mathrm{~W}$, wavelength $\lambda=900-1030 \mathrm{~nm}$ ), Kuka KR16-2 industrial robot (equipped with six axes and maximum range $1610 \mathrm{~mm}$ ) and DMG/Mori Seiki CTX 310 eco lathe. The laser head was connected with an industrial robot (Fig.5a), and thus, the laser beam was moving along the turning axis with the linear speed equaled to the feedrate $v_{f}$. The tool's angular distance from the laser beam was selected as $\theta=35^{\circ}$ (Fig. 5b).

The measurements of cutting forces were conducted in the range of variable feed $f$ and cutting speed values $v_{c}$. The force measurements were repeated three times for each combination of the input parameters applied during the LAM tests. The design of the experiment carried out is presented in Table 2.

During the precision machining carried out with relatively low values of cutting depth and feed, the measured forces also reach low values. Consequently, the applied force
Fig. 3 The general scheme of the proposed minimum uncut chip thickness estimation method

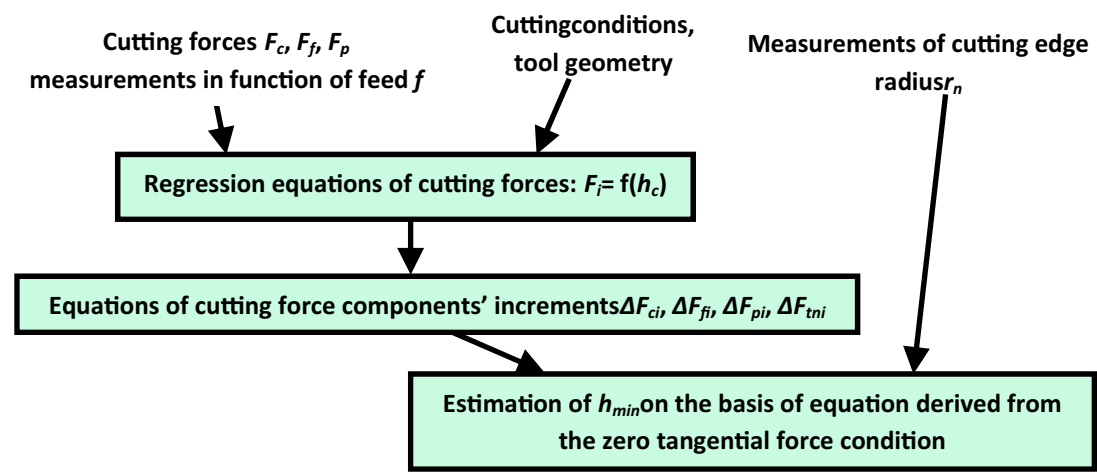


Fig. 4 Microstructure of WC/ $\mathrm{NiCr}$ laser clad. a On the circumference of the sample. $\mathbf{b}$ Cross-section through coating (a)

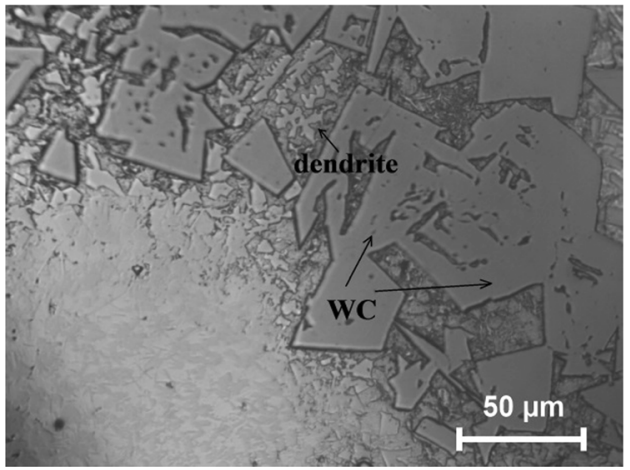

(b)

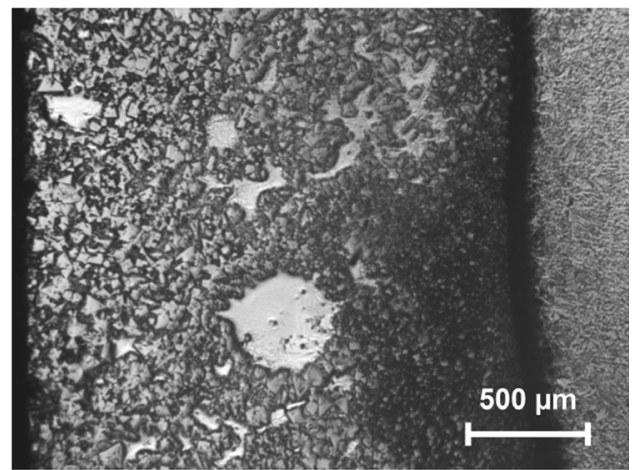

dynamometer must be characterized by a high sensitivity. Nevertheless, the measured force signals consist of the components connected directly with turning kinematics (described by the spindle frequency $f_{o}$ and its harmonics $2 f_{o}$ ), as well as the disturbances caused by the dynamical properties of the machine-work piece-toolholder-dynamometer system (e.g. toolholder's natural frequency, work piece's natural frequency, dynamometer's frequency). Therefore, in order to exclude these dynamical interferences from the measured signals, the low-pass filters can be applied. However, the identification of the effective cut off frequency $f_{c}$ requires also the determination of the machining system's natural frequencies. These quantities have been obtained on the basis of the conducted impulse test (Fig. 6).

Subsequently, the cut off frequency has been calculated on the basis of the equation

$f_{c} \approx 2 f_{o}+10 \%$

Cutting forces $\left(F_{c}, F_{f}, F_{p}\right)$ were measured using a piezoelectric three-component Kistler 9257B force dynamometer connected through the $5070 \mathrm{~A}$ Kistler multi-channel charge
Fig. 5 The LAM of WC/NiCr clad layer. a The LAM stand. b The designation of tool angular distance from the laser beam. c Schematic diagram of force measurement set-up a)

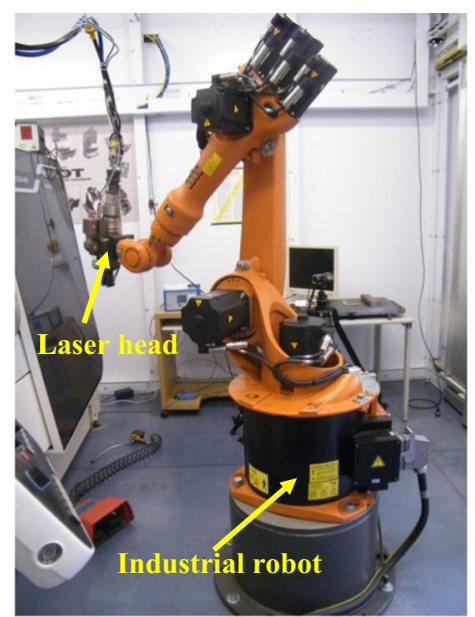

b)

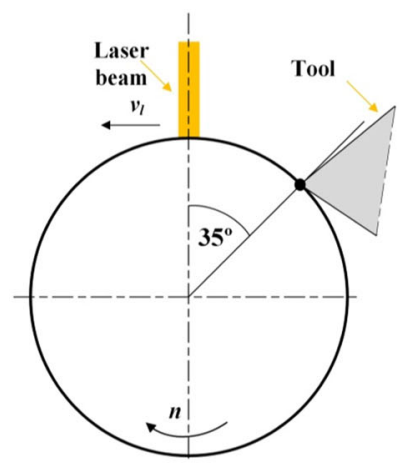

c)

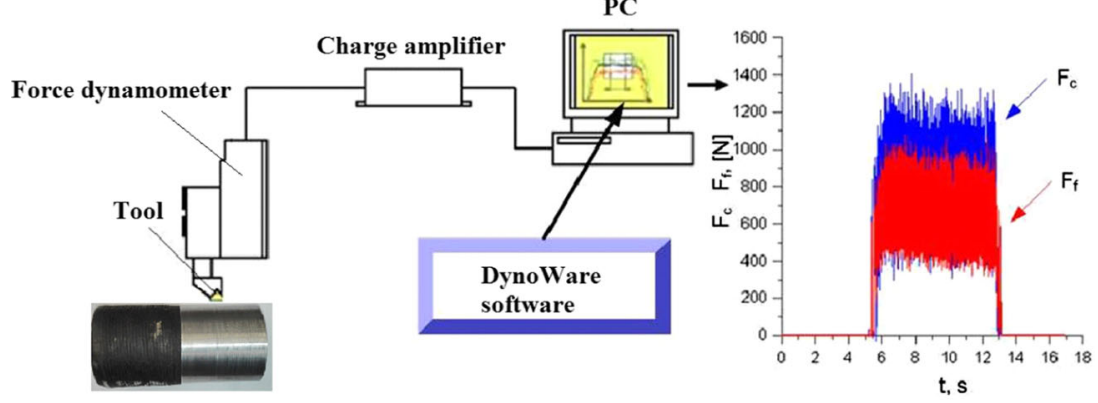

Work piece 
Table 2 Design of experiment

\begin{tabular}{|c|c|c|c|c|c|c|c|c|c|}
\hline $\begin{array}{l}\text { Distance from } \\
\text { laser beam } \\
\theta\left[^{\circ}\right]\end{array}$ & $\begin{array}{l}\text { Laser spot } \\
\text { diameter } d_{l} \\
{[\mathrm{~mm}]}\end{array}$ & $\begin{array}{l}\text { Laser power } \\
P[\mathrm{~W}]\end{array}$ & $\begin{array}{l}\text { Depth of cut } \\
a_{p}[\mathrm{~mm}]\end{array}$ & $\begin{array}{l}\text { Cutting length } \\
l[\mathrm{~mm}]\end{array}$ & $\begin{array}{l}\text { Cutting speed } \\
v_{c}[\mathrm{~m} / \mathrm{min}]\end{array}$ & $\begin{array}{l}\text { Sample diameter } \\
D[\mathrm{~mm}]\end{array}$ & $\begin{array}{l}\text { Rotational } \\
\text { speed } n \\
{[\mathrm{rev} / \mathrm{min}]}\end{array}$ & $\begin{array}{l}\text { Feedrate } v_{f} \\
{[\mathrm{~mm} / \mathrm{min}]}\end{array}$ & $\begin{array}{l}\text { Feed } f \\
{[\mathrm{~mm} /} \\
\text { rev }]\end{array}$ \\
\hline 35 & 2 & 1400 & 0.1 & 10 & $\begin{array}{l}10-30 \\
\quad \text { interval } 10\end{array}$ & 52 & $60-173$ & $1.8-34$ & $0.03-0.2$ \\
\hline
\end{tabular}

amplifier to a data acquisition computer (see-Fig. 5c). The sensitivity of the applied force dynamometer was of 3.7 to $7.5 \mathrm{pC} / \mathrm{N}$. The force signal sampling frequency was equaled to $1000 \mathrm{~Hz}$.

The force components were defined in the tool's coordinate system as cutting (main) force $F_{c}[\mathrm{~N}]$, feed force $F_{f}[\mathrm{~N}]$ and thrust force $F_{p}[\mathrm{~N}]$. The acquisition of the force signal was made with the aid of DynoWare software. This software was also used to calculate the signals' mean arithmetic values, which were further applied in the carried out analyses.

\subsection{Results and discussion}

Figure 7 depicts the experimental values of cutting forces $F_{c}$, $F_{f}, F_{p}$ and edge forces $F_{c e}, F_{f e}, F_{p e}$ expressed in function of uncut chip thickness $h_{c}$ and cutting speed $v_{c}$. It can be seen that independently of cutting speed value and force direction, the cutting forces are growing together with an increase of the uncut chip thickness. This is a typical dependency observed during machining of metals. However, Fig. $7 \mathrm{a}-\mathrm{c}$ reveal also that some discrepancies between the experimental force values and the linear regression equations are found. These differences are also confirmed by the correlation coefficients $R^{2}$ of force regression equations (see-Table 3) with values which are not exceeding 0.91 . The reason of this phenomenon is connected directly with the structure of the WC/NiCr sample (Fig. 4), which consists of hard reinforcing WC phase and softer NiCr matrix. During the machining of the $\mathrm{WC} / \mathrm{NiCr}$ at the low cutting depths, the tool cuts alternately the reinforcing phase and matrix, which consequently induces force oscillations, and thus nonlinearities in function of uncut chip thickness.

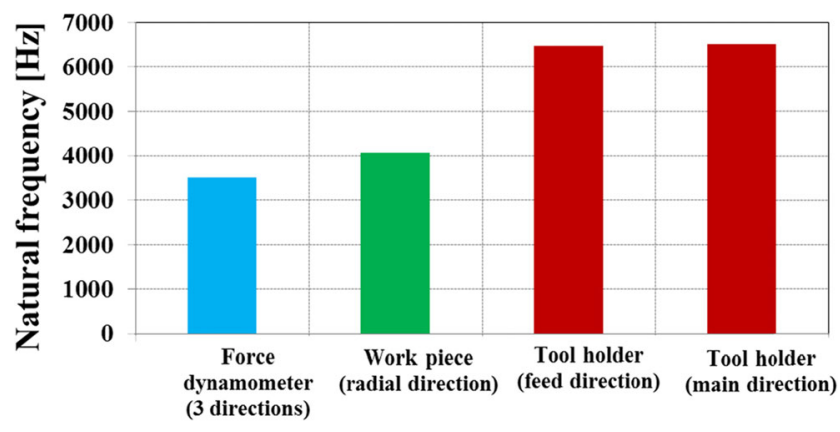

Fig. 6 The natural frequencies measured during impulse test
Figures $7 \mathrm{a}-\mathrm{c}$ reveal also that independently of the selected cutting speed value, the highest values of forces are obtained for the thrust component $F_{p}$, then for the cutting force $F_{c}$. The lowest force values are observed in the case of the feed component $F_{f}$. This dependency stays in agreement with that observed during cutting of hardened steels [41]. The highest thrust forces values, in comparison to the remaining force directions, occurring during cutting with the low selected cutting depths are caused by the chip formation in the region of the tool's corner radius, as well as the abrasion of hard WC particles on the tool's flank face.

The same quantitative relations between the force directions can be also found in case of the edge forces $F_{c e}, F_{f e}$, $F_{p e}$ (Fig. 7d). The $F_{c e}, F_{f e}, F_{p e}$ components characterize the contact conditions in the machined surface-tool flank interface at the zero uncut chip thickness value.

Figure $7 \mathrm{~d}$ shows that the growth of cutting speed causes the monotonic increase in edge forces. The observed differences between the forces are exceeding $290 \%$ (in case of thrust component $F_{p e}$ ). It should be noted that the excessive edge forces can lead to the accelerated tool wear. Therefore, during the LAM of WC/NiCr, the selection of lower cutting speeds can be advantageous in terms of the elongation of the tool life.

Figures 8a-c presents the measured $F_{c}, F_{f}, F_{p}$ forces in function of feed $f$ and cutting speed $v_{c}$. It can be seen that $F_{c}, F_{f}, F_{p}$ forces are growing together with the growth of the feed value, independently on the selected cutting speed.

This dependency is attributed to the proportionality of the feed to the uncut chip thickness. In addition, the growth of cutting speed induces the increase of $F_{c}, F_{f}, F_{p}$ forces' values, for the all investigated feeds $f$.

It should be noted that during conventional cutting (without the laser assistance) of hard materials, the growth of cutting speed usually causes the growth of the temperature in the cutting zone, which in turn leads to the softening of the work piece and thus reduction of cutting forces [42]. However, in case of LAM, the growth of the rotational speed reduces the heat transfer between the laser beam and the heated surface and thus causes the decline in machined surface's temperature [43]. Consequently, the softening of the hard WC/NiCr material is limited, which can result in the growth of cutting force components' values.

The force regression equations presented in Table 3 were applied to the formulation of tangential force increments' 
(a)

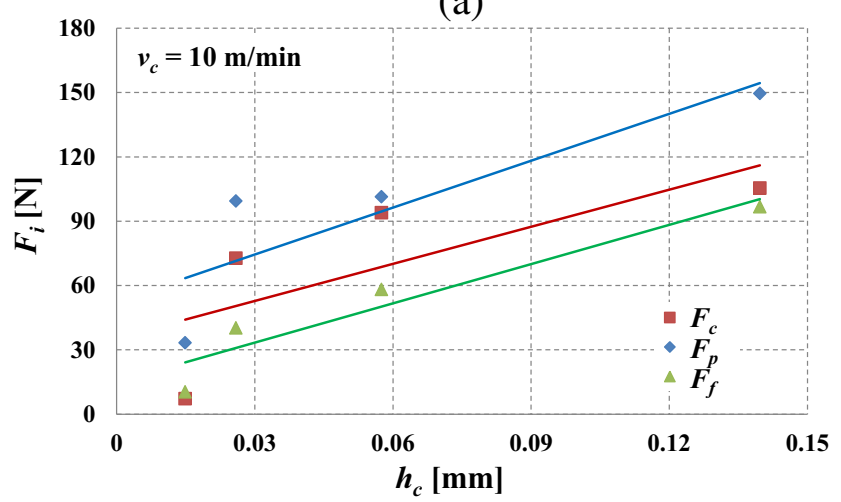

(b)

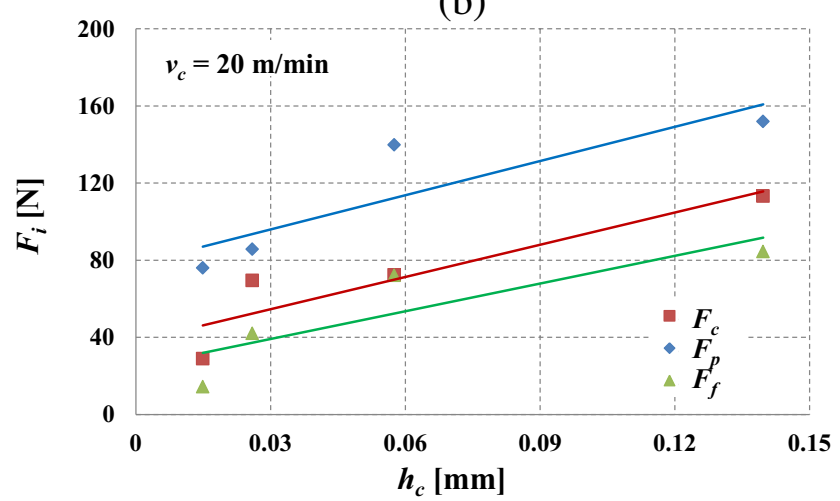

(c)

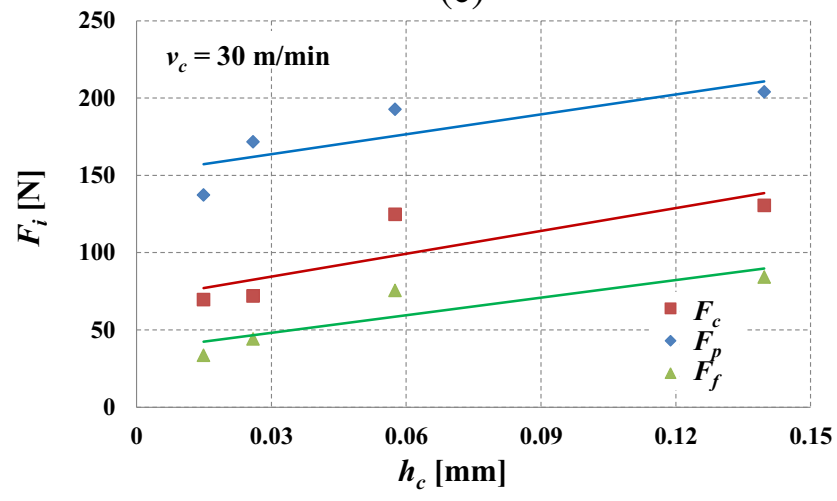

(d)

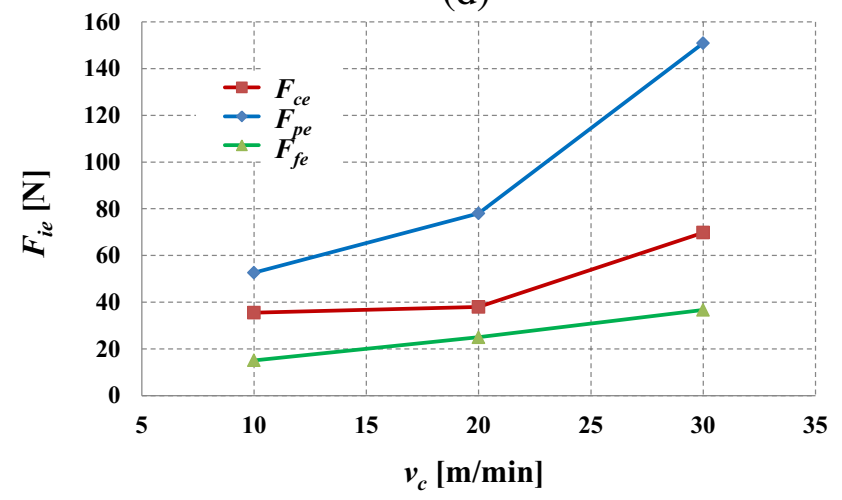

Fig. 7 The measured forces. a $F_{c}, F_{f}, F_{p}=\mathrm{f}\left(h_{c}\right)$ for $v_{c}=10 \mathrm{~m} / \mathrm{min} . \mathbf{b} F_{c}$, $F_{f}, F_{p}=f\left(h_{c}\right)$ for $v_{c}=20 \mathrm{~m} / \mathrm{min} . \mathbf{c} F_{c}, F_{f}, F_{p}=f\left(h_{c}\right)$ for $v_{c}=30 \mathrm{~m} / \mathrm{min} . \mathbf{d}$ Edge forces $F_{c e}, F_{f e}, F_{p e}=f\left(v_{c}\right)$
$\Delta F_{t n}$ in function of uncut chip thickness (Fig. 9). Figure 9 shows that $\Delta F_{t n}$ force increments are distributed nonlinearly along the curved cutting edge. The highest values of the $\Delta F_{t n}$ are found during LAM with the $v_{c}=10 \mathrm{~m} / \mathrm{min}$, then for the machining with $v_{c}=20 \mathrm{~m} / \mathrm{min}$ and finally in case when $v_{c}=30 \mathrm{~m} / \mathrm{min}$. This is an opposite trend towards that observed for the cutting force components $F_{c}, F_{f}, F_{p}$. In addition, the analysis of the $\Delta F_{t n}$ distribution along the curved cutting edge allows the determination of minimum uncut chip thickness $h_{\min }$. According to Eq. (7), the $h_{\min }$ is defined for the $\Delta F_{t n}=0$. Therefore, the intersection point of the $\Delta F_{t n}=\mathrm{f}\left(h_{c}\right)$ curve with the $h_{c}$ axis corresponds precisely to the minimum uncut chip thickness value (see the black dashed lines in Fig. 9). It should be also noted that the negative $\Delta F_{t n}$ force increments are correlated with the ploughing mechanism occurring between the curved cutting edge and the deformed work piece, whereas the positive $\Delta F_{t n}$ force increments are connected with the chip shearing phenomenon.

The normalized minimum uncut chip thickness values, expressed as the quotient of minimum uncut chip thickness to cutting edge radius $h_{\min } / r_{n}$, are presented in Fig. 10a. The investigations carried out revealed that during LAM of WC/ $\mathrm{NiCr}$, the $h_{\min } / r_{n}$ factor is contained in the range of $0.15-0.25$. This observation is consistent with the results presented in [44] and [45], which show that the normalized minimum uncut chip thickness values during machining of metallic materials are usually within the range of $0.05-0.38$. Furthermore, the $h_{\mathrm{min}} / r_{n}$ values are lower during LAM of WC/NiCr in comparison to that obtained during machining of 1040 steel and A16082-T6 alloy. Therefore, it can be also suggested that normalized minimum uncut chip thickness is dependent on the work piece hardness and the shear angle during cutting [34].

Figure $10 \mathrm{~b}$ shows that the minimum uncut chip thickness values generated during LAM of $\mathrm{WC} / \mathrm{NiCr}$ depended on the selected cutting speed value. The $h_{\min }$ values are growing together with the growth of the cutting speed and are contained in the range of 1.1-1.8 $\mu \mathrm{m}$. According to Bifano et al. [11] and Stephenson et al. [12], cutting of hard materials

Table 3 Regression equations of forces

\begin{tabular}{lll}
\hline$v_{c}[\mathrm{~m} / \mathrm{min}]$ & The form of equation & Coefficient $R^{2}$ \\
\hline 10 & $F_{c}=577 h_{c}+36$ & 0.91 \\
& $F_{f}=610 h_{c}+15$ & 0.55 \\
& $F_{p}=729 h_{c}+53$ & 0.74 \\
20 & $F_{c}=556 h_{c}+38$ & 0.83 \\
& $F_{f}=479 h_{c}+25$ & 0.74 \\
30 & $F_{p}=591 h_{c}+78$ & 0.77 \\
& $F_{c}=492 h_{c}+70$ & 0.71 \\
& $F_{f}=379 h_{c}+37$ & 0.77 \\
& $F_{p}=428 h_{c}+151$ & 0.68
\end{tabular}


Fig. 8 The force components in function of cutting speed and feed. a Cutting force $F_{c}$. b Feed force $F_{f}$. Thrust force $F_{p}$ (a)
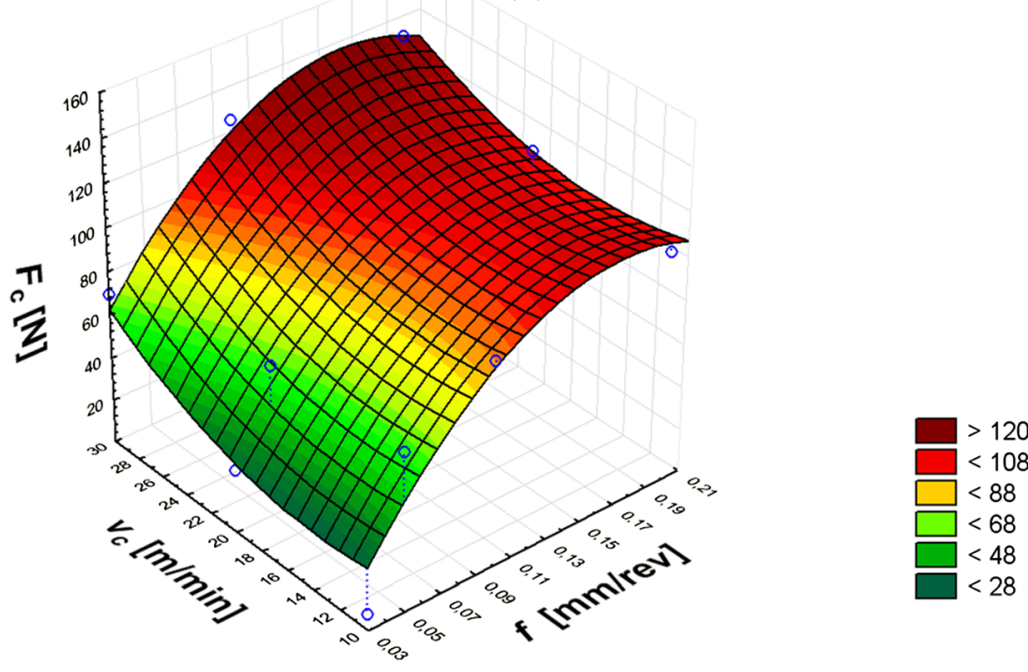

(b)

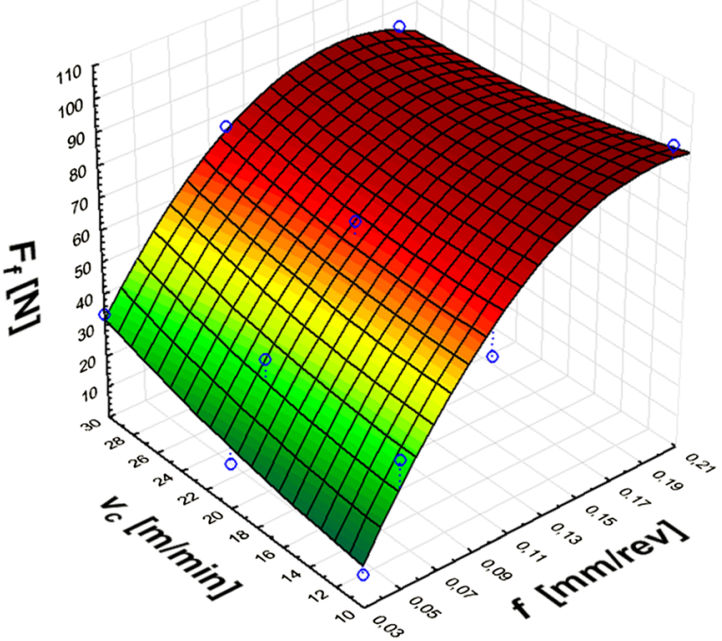

$>90$

$<84$

$<74$

$\square<64$

$\longrightarrow 54$

$\square<44$

$<34$

$<24$

(c)

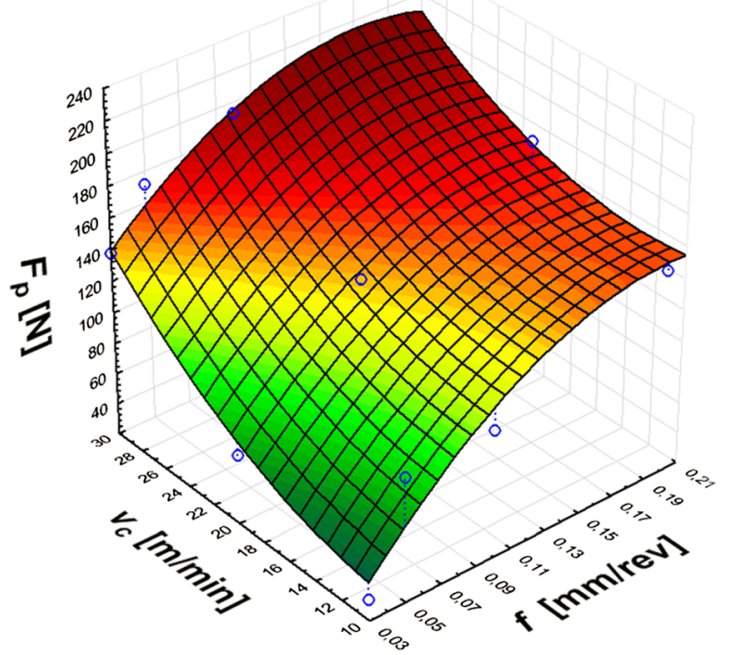


Fig. 9 The tangential force increments' $\Delta F_{t n}$ in function of uncut chip thickness

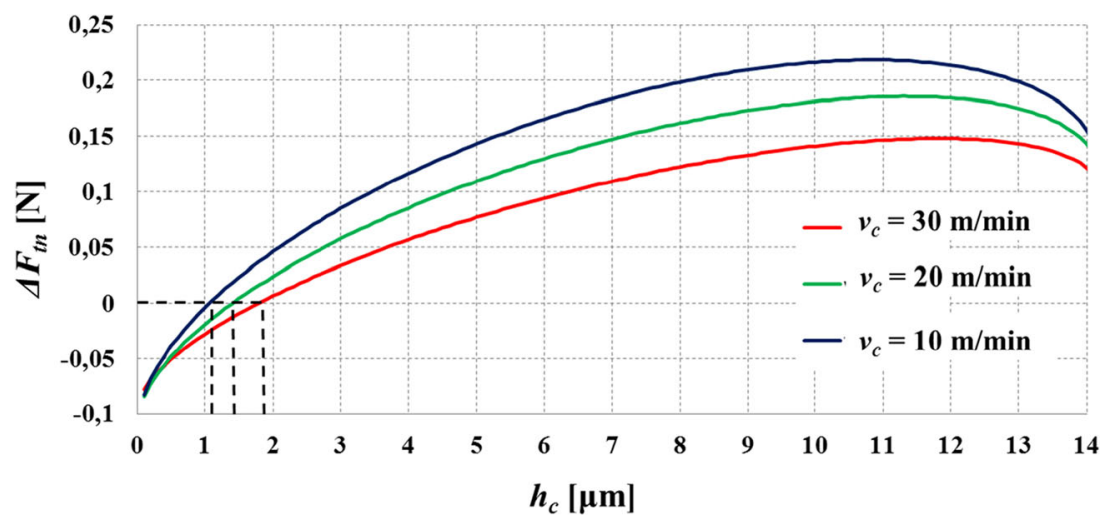

with the selection of uncut chip thicknesses corresponding to the $h_{\text {min }}$ value enables the chip formation in the ductile mode, which in turn reduces the amount of cracks and damages on the machined surface. Nevertheless, it can also lead to the excessive growth of the ploughing force and consequently the intense tool wear. Therefore, in order to soften the hard $\mathrm{WC} / \mathrm{NiCr}$ material during cutting, together with the maintaining relatively high tool life, the laser-assisted machining can be applied. However, this process should be carried out with cutting conditions corresponding to uncut chip thicknesses larger than the minimum uncut chip thickness.

The reliable estimation of minimum uncut chip thickness has also the significant meaning in relation to the surface roughness prediction. According to Schultheiss et al. [46], the application of the surface roughness model considering kinematic-geometric dependencies and elastic-plastic deformations of work piece (related to $h_{\min }$ ) enables the accurate prediction of $R a$ and $R z$ roughness parameters during precision turning with low feed values. Therefore, the results obtained in this research can be further applied to the optimal selection of cutting parameters during LAM of WC/NiCr clad layers, enabling the obtainment of high surface quality.

It should be also noted that the proposed method of minimum uncut chip thickness estimation is dedicated precisely to oblique cutting processes. However, the majority of approaches reported in the literature are focused only on the orthogonal cutting. In practice, the precision machining operations are usually carried out in oblique cutting conditions.
Therefore, the developed model can be also applied to the estimation of minimum uncut chip thickness during micromilling and micro-drilling operations.

\section{Conclusions}

This paper was focused on the estimation of minimum uncut chip thickness and analysis of cutting forces during laserassisted machining of $\mathrm{WC} / \mathrm{NiCr}$ clad layer. The research involved the application of the zeroth tangential force increment method, extended to the oblique cutting. Based on the experimental results, the following conclusions have been formulated.

- The growth of cutting force components together with an increase in uncut chip thickness is observed, independently on the selected cutting speed value. However, some discrepancies between the experimental forces and the linear regression equations are found. It should be noted that these differences can affect the accuracy of the method applied for the estimation of minimum uncut chip thickness, which is based on the assumption that the uncut chip thickness has a linear effect on cutting forces.

- During LAM of WC/NiCr clad layers, cutting speed is an important factor affecting cutting mechanics. The growth of its value causes the growth of cutting forces $F_{c}, F_{f}, F_{p}$ and minimum uncut chip thicknesses $h_{\text {min }}$, as well as the
Fig. 10 Minimum uncut chip thickness. a The comparison of the normalized minimum uncut chip thickness. b Minimum uncut chip thickness during LAM of $\mathrm{WC} / \mathrm{NiCr}$ for the various cutting speed values (a)

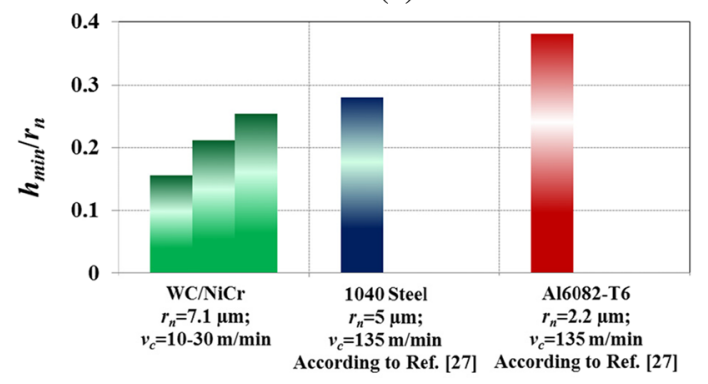

(b)

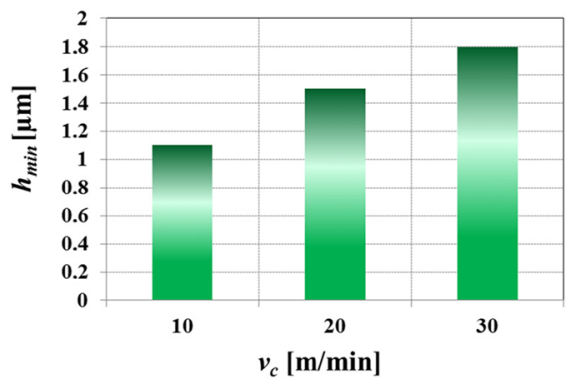


decline of tangential force increments $\Delta F_{t n}$ along the curved cutting edge.

- The minimum uncut chip thicknesses, estimated for the $\mathrm{WC} / \mathrm{NiCr}$ clad layer fit into the range specified for the metallic materials. The estimated $h_{\min } / r_{n}$ factor values are contained in the range of $0.15-0.25$, and thus their values are lower than that obtained during machining of 1040 steel and A16082-T6 alloy. The knowledge of $h_{\min }$ value has a significant meaning in terms of the selection of cutting conditions during machining of $\mathrm{WC} / \mathrm{NiCr}$. The application of LAM enables the softening of hard and brittle work piece and thus facilitates the chip decohesion in the ductile regime. Therefore, during LAM of WC/ $\mathrm{NiCr}$, the selected cutting conditions' values should be higher than those applied in the ultraprecision machining, i.e. uncut chip thickness $h$ larger than minimum uncut chip thickness $h_{\min }$.

- The proposed method can be successfully applied to the estimation of minimum uncut chip thickness during various oblique cutting methods (e.g. milling, drilling) and for the diversified materials.

Acknowledgements This work was supported by National Centre for Research and Development (NCBiR) of Poland grant no. LIDER/005/ 141/L-5/NCBR/2014, project: "Laser-assisted machining of sintering carbide deposited by laser cladding".

Open Access This article is distributed under the terms of the Creative Commons Attribution 4.0 International License (http:// creativecommons.org/licenses/by/4.0/), which permits unrestricted use, distribution, and reproduction in any medium, provided you give appropriate credit to the original author(s) and the source, provide a link to the Creative Commons license, and indicate if changes were made.

\section{References}

1. Bartkowska A, Przestacki D, Chwalczuk T (2016) Microstructure, phase composition and corrosion resistance of $\mathrm{Ni} 2 \mathrm{O} 3$ coatings produced using laser alloying method. Arch Mech Tech Mater. doi:10.1515/amtm-2016-0005

2. Cus F, Zuperl U, Irgolic T (2002) Effects of laser cladding parameters on microstructure properties and surface roughness of graded material. Proceedings in Manufacturing Systems 10(2):77-82

3. Nieslony P, Cichosz P, Krolczyk GM, Legutko S, Smyczek D, Kolodziej M (2016) Experimental studies of the cutting force and surface morphology of explosively clad Ti-steel plates. Measurement 78:129-137

4. Wojciechowski S, Twardowski P, Chwalczuk T (2014) Surface roughness analysis after machining of direct laser deposited tungsten carbide. J Phys Conf Ser 483(1). doi:10.1088/1742-6596/483 $/ 1 / 012018$

5. Hur J, Lee K, Zhu-hu KJ (2002) Hybrid rapid prototyping system using machining and deposition. Comput Aided Des 34:741-754

6. Jeng J-Y, Lin M-C (2001) Mold fabrication and modification using hybrid processes of selective laser cladding and milling. J Mater Process Technol 110:98-103
7. Paul CP, Alemohammad H, Toyserkani E, Khajepour A, Corbin S (2007) Cladding of WC-12 Co on low carbon steel using a pulsed Nd:YAG laser. Mater Sci Eng A 464:170-176

8. Guo C, Chen J, Zhou J, Zhao J, Wang L, Yu Y, Zhou H (2012) Effects of WC-Ni content on microstructure and wear resistance of laser cladding Ni-based alloys coating. Surface \& Coatings Technology 206:2064-2071

9. Chiang KA, Chen YC (2007) Microstructural characterization and microscopy analysis of laser cladding Stellite12 and tungsten carbide. J Mater Process Technol 182:297-302

10. GisarioA PM, Venettacci S, Veniali F (2015) Improvement of thermally sprayed $\mathrm{WC}-\mathrm{Co} / \mathrm{NiCr}$ coatings by surface laser processing. Int Journal of Refractory Metals and Hard Materials 52:123-130

11. Bifano TG, Dow TA, Scattergood RO (1991) Ductile-regime grinding: a new technology for machining brittle materials. ASME J Eng Ind 113(5):184-189

12. Stephenson DJ, Vaselovac D, Manley S, Corbett J (2001) Ultraprecision grinding of hard steels. Precis Eng 25(4):336-345

13. Liu K, Li XP (2001) Modelling of ductile cutting of tungsten carbide. Trans NAMRI/SME 29:251-258

14. Liu K, Li XP (2001) Ductile cutting of tungsten carbide. J Mater Process Technol 113:348-354

15. Liu K, Li XP, Rahman M, Liu XD (2003) CBN tool wear in ductile cutting of tungsten carbide. Wear 255:1344-1351

16. Yan J, Zhang Z, Kuriyagawa T (2009) Mechanism for material removal in diamond turning of reaction-bonded silicon carbide. International Journal of Machine Tools \& Manufacture 49:366-374

17. Twardowski P (2011) Surface roughness analysis in milling of tungsten carbide with CBN cutters. MetrolMeasSystXVIII 1:105114

18. Dumitrescu P, Koshy P, Stenekes J, Elbestawi MA (2006) Highpower diode laser assisted hard turning of AISI D2 tool steel. International Journal of Machine Tools \& Manufacture 46:20092016

19. Novak JW, Shin YC, Incropera FP (1997) Assessment of plasmaenhanced machining for improved machinability of Inconel 718. ASME Journal of Manufacturing Science and Engineering 119:125-129

20. Leshock CE, Kim JN, Shin YC (2001) Plasma enhanced machining of Inconel 718: modeling of workpiece temperature with plasma heating and experimental results. Int J Mach Tools Manuf 41:877897

21. Sun S, Brandt M, Dargusch MS (2010) Thermally enhanced machining of hard-to-machine materials-a review. International Journal of Machine Tools \& Manufacture 50:663-680

22. Sun S, Harris J, Q (2008) Parametric investigation of laser-assisted machining of commercially pure titanium. Adv Eng Mater 10:565572

23. Germain G, Morel F, Lebrun J-L, Morel A (2007) Machinability and surface integrity for a bearing steel and a titanium alloy in laser assisted machining (optimisation on LAM on two materials). Lasers in Engineering 17:329-344

24. Lei S, Shin YC, Incropera FP (2001) Experimental investigation of thermo-mechanical characteristics in laser assisted machining of silicon nitride ceramics. Journal of Manufacturing Science and Engineering Transactions of the ASME 123:639-646

25. Pfefferkorn FE, Shin YC, Incropera FP, Tian Y (2004) Laserassisted machining of magnesia-partially-stabilized zirconia. Journal of Manufacturing Science and Engineering. Transactions of the ASME 126:42-51

26. Wang Y, Yang LJ, Wang NJ (2002) An investigation of laserassisted machining of $\mathrm{Al} 2 \mathrm{O} 3$ particle reinforced aluminum matrix composite. J Mater Process Technol 129:268-272

27. Dandekar CR, Shin YC (2013) Multi-scale modeling to predict subsurface damage applied to laser-assisted machining of a particulate 
reinforced metal matrix composite. J Mater Process Technol 213: 153-160

28. Przestacki D, Szymanski P, Wojciechowski S (2016) Formation of surface layer in metal matrix composite A359/20SiCP during laser assisted turning. Compos A: Appl Sci Manuf 91 1:370-379

29. Przestacki D (2014) Conventional and laser assisted machining of composite A359/20SiCp. Procedia CIRP 14:229-233

30. Chae J, Park SS, Freiheit T (2006) Investigation of micro-cutting operations. International Journal of Machine Tools \& Manufacture 46:313-332

31. Camara MA, Abrao AM, Rubio JCC, Godoy GCD, Cordeiro BS (2016) Determination of the critical undeformed chip thickness in micromilling by means of the acoustic emission signal. Precis Eng 46:377-382

32. de Oliveira FB, Rodrigues AS, Coelho RT, de Souza AF (2015) Size effect and minimum chip thickness in micromilling. International Journalof Machine Tools \& Manufacture 89:39-54

33. Kragelsky IV, Dobychin MN, Kombalov VS (1977) Friction and wear-calculation methods. PergamonPress, New York

34. Liu X, DeVor RE, Kapoor SG (2006) An analytical model for the prediction of minimum chip thickness in micromachining. Transactions of the ASME 128:474-481

35. Lai X, Li H, Li C, Lin Z, Ni J (2008) Modelling and analysis of micro scale milling considering size effect, micro cutter edge radius and minimum chip thickness. International Journal of Machine Tools \& Manufacture 48:1-14

36. Moriwaki T, Sugimura N, Luan S (1993) Combined stress material flow and heat analysis of orthogonal micromachining of copper. Annals of CIRP 42:75-78
37. Malekian M, Mostofa MG, Park SS, Jun MBG (2012) Modeling of minimum uncut chip thickness in micro machining of aluminium. $\mathrm{J}$ Mater Process Technol 212:553-559

38. Storch B, Zawada-Tomkiewicz A (2012) Distribution of unit forces on the tool edge rounding in the case of finishing turning. Int $\mathrm{J}$ AdvManufTechno 160:453-461

39. Wojciechowski S, Maruda RW, Nieslony P, Krolczyk GM (2016) Investigation on the edge forces in ball end milling of inclined surfaces. Int J Mech Sci 119:360-369

40. Amado JM, Tobar MJ, Yanez A, Amigo V, Candel JJ (2011) Crack free tungsten carbide reinforced $\mathrm{Ni}(\mathrm{Cr})$ layers obtained by laser cladding. Phys Procedia 12:338-344

41. Tonshoff HK, Arendt C, Ben Amor R (2000) Cutting of hardened steel. Annals of the CIRP 49(2):546-566

42. Dewes RC, Aspinwall DK (1997) A review of ultra high speed milling of hardened steels. J Mater Process Technol 69:1-17

43. Przestacki D, Jankowiak M (2014) Surface roughness analysis after laser assisted machining of hard to cut materials. Journal of Physics: Conference Series 483

44. Weule H, Huntrup V, Tritschle H (2001) Micro-cutting of steel to meet new requirements in miniaturization. CIRP Ann 50:61-64

45. Filiz S, Conley CM, Wasserman MB, Ozdoganlar OB (2007) An experimental investigation of micro-machinability of copper 101 using tungsten carbide micro-endmills. Int J Mach Tools Manuf 47(7-8):1088-1100

46. Schultheiss F, Hagglund S, Bushlya V, Zhou J, Stahl J-E (2014) Influence of the minimum chip thickness on the obtained surface roughness during turning operations. Procedia CIRP 13:67-71 